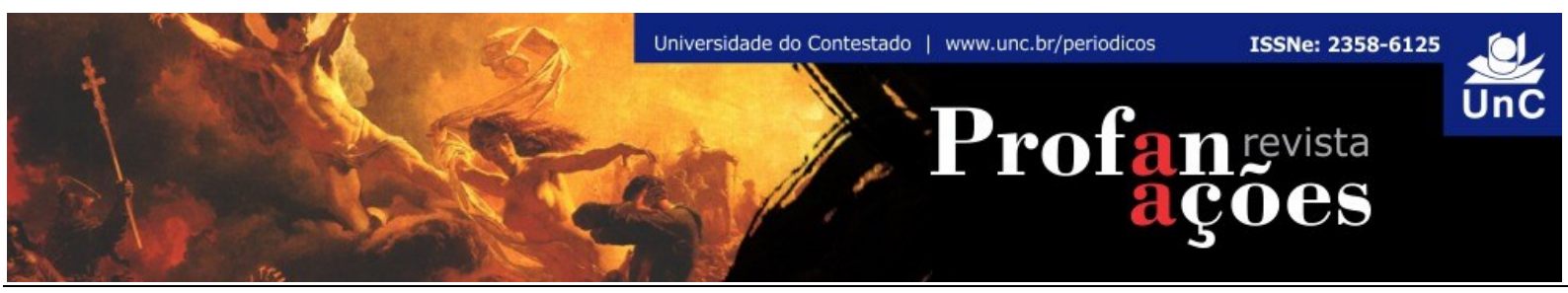

\title{
A CIDADE COMO CATIVEIRO
}

Marcos Sardá Vieira ${ }^{1}$

RESUMO: Ao problematizar a condição urbana e social estabelecida no século 19, baseada na razão e nos avanços da técnica, este artigo apresenta uma reflexão sobre a cidade como meio de apropriação do espaço e do tempo da humanidade, preconizando maior atenção na interação com a tecnologia do que em relação às necessidades e desejos humanos. A manutenção desta realidade onde a tecnológica torna-se sagrada, a vida humana secundária e a natureza profana, tende a ser a ordem para a constituição da cultura material em vigor. Desta maneira, a cidade encena o fim da vida como obra de arte e, cada vez mais, se torna um lugar cativo, acionado por dispositivos simultâneos de atração e aprisionamento.

Palavras-chave: Cidade. Modernidade. Técnica. Planejamento urbano.

\section{THE CITY AS CAPTIVITY}

ABSTRACT: Challenging the urban and social condition established in the 19th century, based on reason and advances in technique, this article presents a reflection on the city as a means of appropriating the space and time of humanity, calling for greater attention in the interaction with technology than in relation to human needs and desires. The maintenance of this reality where the technological becomes sacred, human life is secondary and nature is profane, tends to be the order for the constitution of material culture nowadays. In this way, the city stages the end of life as a work of art and, increasingly, becomes a captive place, driven by simultaneous devices of attraction and entrapment.

Keywords: City. Modernity. Technical. Urban plan.

\footnotetext{
${ }^{1}$ Arquiteto, urbanista a professor da Universidade Federal da Fronteira Sul (UFFS). Atualmente, doutorando interdisciplinar em Ciências Humanas pela Universidade Federal de Santa Catarina (UFSC). Universidade Federal da Fronteira Sul (UFFS). Santa Catarina. Brasil: E-mail: marcosarda@gmail.com
} 


\section{INTRODUÇÃO}

Décadas antes do modelo de planejamento urbano moderno ser concebido pelo CIAM - Congresso Internacional de Arquitetura Moderna, no início do século 20, partindo da ideia da cidade como máquina, setorizada em funções predeterminadas e constituindo espaços padronizados - a cidade já vinha perdendo seu caráter de espaço múltiplo, como lugar do encontro, da diversidade, dos diálogos e das peculiaridades. De ambiente de proteção e abrigo coletivo a cidade se transformou em locação da indústria, tornando-se o lugar da produção material e tecnológica, que em nada substituem a vida presencial e contemplativa do contato direto com a paisagem e do encontro ocasional com o sujeito qualquer (AGAMBEN, 2013; JACOBS, 2011).

Partindo deste ponto de vista inicial e com enfoque interdisciplinar, o objetivo deste artigo é refletir a condição estabelecida pela modernidade sobre o contexto urbano atual. Para isso são problematizados alguns fatores que levam à alienação da sociedade diante dos princípios da razão e da técnica, ambientados pelo maior dispositivo de regulamentação social: a cidade.

$\mathrm{Na}$ sequência do texto, interpretamos esta reflexão como oportunidade para questionar a cosmovisão metafísico-racional, "num exercício crítico, criativo, lúdico e pleno de alegria vital como condição de transformar a vida numa obra de arte" (BAZZANELLA; ASSMANN, 2013, p. 84).

\section{PRESSUPOSTOS URBANOS DA MODERNIDADE}

De acordo com Harvey (2015), Brandão (2014) e Sêga (2000), a definição do modelo de estrutura urbana onde vivemos hoje foi estabelecida na segunda metade do século 19, atendendo aos interesses de crescimento da produção industrial e do mercado consumidor. Segundo estes autores, todo o cenário de reformas urbanas, promovidas neste período, serviu como suporte físico para consolidar o poder de comerciantes e especuladores imobiliários, para minimizar a possibilidade de revoltas populares no espaço público e para segregar a população pobre longe do espaço central e espetacular da cidade. 
Ao mesmo tempo em que o espaço urbano foi transformado em modelo de planejamento, também foi preciso (re)modelar o perfil da população para dar conta do funcionamento desta nova estrutura/cultura urbana e industrial. $\mathrm{Na}$ adequação das pessoas para viver neste modelo de ambiente artificial, negando o vínculo humano com a natureza, foi necessário disciplinar o corpo, a subjetividade e os desejos de homens e mulheres. Este conjunto de regulamentações fez parte dos princípios herdados e aprimorados ao longo do século 20, através do controle pastoral e da biopolítica ${ }^{2}$ (FOUCAULT, 2006). Por isso, esta regulamentação permanece na forma de dispositivos, construídos para atender as necessidades dimensionais do controle social e da produtividade econômica, usurpando da participação de grupos sociais e individuais, confinados no território da soberania irrevogável e por uma identidade nacional inquestionável. Neste sentido, a cidade contemporânea representa o limite desta extensão física e simbólica de condicionamento da vida das pessoas ${ }^{3}$.

Esta concepção de modernidade vem sendo estabelecida desde o século 16, com a dissolução do mundo feudal e com o início do processo de industrialização, que afastou a relação do sujeito com a natureza, inserido a população citadina em um processo de recursos artificiais, desviando a passagem da potencia humana, do tempo de contemplação e reflexão, para o ato automático das atividades urbanas (AGAMBEN, 2013).

Ao longo destes últimos cinco séculos de consolidação da modernidade até a atualidade, mudanças substanciais foram promovidas nas relações entre o sujeito e o objeto no âmbito privado e a atuação política e coletiva na esfera pública. Por isso, é no contexto urbano de materialização desta realidade mecânica e tecnológica onde a restrição da liberdade de atuações humanas torna-se mais factível e totalitária. Neste caso, a compreensão da liberdade como processo de conquista ininterrupto, que resulta em um lugar de pertencimento consentido.

Para a filósofa Hannah Arendt (2000)

2 De acordo com Michel Foucault, biopolítica é a maneira como o poder, no final do século 19, se apropria da condição de vida humana: do corpo, da saúde e da reprodução.

3 Vidas precárias diante da expansão geopolítica do capitalismo e do desenvolvimento tecnológico (BUTLER, 2015). 
o conceito de liberdade está intimamente ligado aos exercícios das atividades públicas. A razão de ser da política e o seu exercício é a liberdade. Caso mulheres e homens não tivessem a potencialidade de estabelecer sua própria realidade, a política não teria sentido algum. A concepção de liberdade como uma conquista individual pelo livre-arbítrio é um obscurecimento herdado do cristianismo. Enquanto a ideia de liberdade através da conquista da propriedade privada e dos direitos civis é uma naturalização do liberalismo. Por conta disso, tanto a tradição cristã quanto a liberal reforçam a ideia de que a liberdade humana está fora da política. $E$ este aspecto compromete a maneira como o ser humano vem a se transformar em sujeitos autônomos, diante da apreensão da realidade onde está inserido (ARENDT, 2000; BERLIN, 1969).

Walter Benjamin (2009) no início do século 20 já anunciava em seus ensaios a ambiguidade entre liberdade e aprisionamento promovidos pela ambiência das grandes metrópoles da Europa do século 19. Em suas publicações, o autor analisa criticamente o processo de adaptações culturais, ficcionais e históricas necessárias para as pessoas se adequarem ao novo modelo de vida "moderna". Neste período, grandes cidades como Paris, Londres e Viena inovaram sua infraestrutura e superestrutura urbanas para atender à concepção ideológica do progresso das sociedades. Em contraste com o campo, as cidades tornaram-se ambientes cativos para o contingente populacional, como se na cidade planejada e homogênea fosse possível reencontrar um sentido para a vida, uma vez que a relação com a terra e a paisagem natural estava sendo perdida, desvalorizada nos resquícios da comunidade feudal.

A busca interminável por esta condição de singularidade que a cidade poderia proporcionar, marcando a angústia do indivíduo vinculado à cidade modernista, torna evidente a incapacidade (ou o despropósito) do planejamento urbano em dar conta deste paradoxo: em construir cidades padronizadas para suprir demandas de particularidades humanas através da razão, da técnica e do acúmulo material. O que nos faz refletir sobre a real intenção deste processo hegemônico de construção da realidade urbana, tendo a cidade como representação deste habitat ideal. Afinal, qual o objetivo geral das cidades, na maneira como são concebidas na atualidade? Será que sua finalidade genérica está associada, efetivamente, ao atendimento dos desejos e necessidades humanas? 


\section{A RAZÃO DE VIVER NA CIDADE}

A cidade, enquanto objeto de estudo, apresenta processos humanos vitais que não a tornam meramente um mecanismo físico ou uma construção artificial. Por esta razão, a cidade deve ser compreendida enquanto sistema de valores materiais e imateriais, que tanto pode facilitar quanto condicionar a vida do ser humano.

Muitas concepções e valores, inclusive, deixam de questionar o propósito da cidade e o fato de haverem poucas alternativas de apropriação espacial para além do modelo atual. Por exemplo, na ideia de crescimento ilimitado para as áreas urbanas, que se tornam um problema de ordem mundial, afetando países centrais e periféricos sob o ritmo de expansão da economia global, onde a noção do impacto local (social, ambiental e cultural) se perde diante dos objetivos de domínio econômico transnacional e da heteronomia do planejamento urbano (WACQUANT, 2010).

É fato que o ponto central do sistema econômico capitalista está no consumo ilimitado, como modo de vida para o qual estamos treinados, constantemente, em acreditar que a boa qualidade de vida é alcançada por intermédio dos valores efêmeros, estabelecidos pela cultura de massa e pela indústria do entretenimento (JAMESON, 2001).

Nesta concepção, nem sempre as dinâmicas urbanas são percebidas pelas sutis alterações na vida cotidiana, quando nos deparamos com a realidade física do ambiente urbano de interações sociais. A vida resiliente da população se mistura com o simulacro neoliberal sustentado por imagens e representações da livre concorrência do mercado, da valorização dos interesses privados sob os públicos e da otimização espacial para atender as demandas deste sistema de produção e especulação (JAMESON, 2001). Por isso, esta articulação estrutural, que condiciona a forma do espaço urbano para atender aos interesses do capital e da produção, reflete a única possibilidade de atuação para os técnicos do planejamento urbano, tendo como resultado fundamental a configuração urbana modernista pautada na desconexão entre o humano e a natureza (ASSMANN; VERNAL, 2015).

O contraponto entre urbanidade e natureza, neste sentido, se circunscreve na visão dualista cartesiana, que marca a condição do ambiente de interações humanas. A construção das cidades sob esta realidade, nos moldes do sistema 
econômico e do desenvolvimento tecnológico, representa o ambiente artificial das práticas individuais, em defesa da propriedade privada. Este costuma ser o fundamento do sistema econômico neoliberal, que prevê leis em defesa dos interesses privados e na minimização das atuações do Estado e do âmbito de reconhecimento público e coletivo. Por isso, a maneira como a estrutura urbana sustenta o desenvolvimento econômico não corresponde ao bem-estar subjetivo e as prerrogativas da qualidade de vida irrestrita para a população. A visão do planejamento urbano a partir de pressupostos racionais e modernistas, consolidados nas reformas urbanas do final do século 19 , continua atendendo aos interesses do capital, onde os fatores humanos são aspectos secundários - apesar de servirem como justificativa para discursos políticos em promoção do desenvolvimento.

Diante desta frágil subordinação da humanidade diante do sistema econômico e produtivista é que o sociólogo Zygmunt Bauman (2009) considera que vivemos em um modelo de sociedade onde a vulnerabilidade é universal. Neste entendimento, diante da violência urbana pode-se pensar que a vulnerabilidade surge devido ao comportamento inóspito e agressivo gerado pelas diferenças socioculturais em disputa pelo direito à cidade. Ou ainda, pela vulnerabilidade de nossa identidade cultural diante dos interesses mercantilistas, do desprestígio da arte diante da banalização das imagens publicitárias e do fracasso individual diante do desenvolvimento tecnológico. Afinal, que vulnerabilidade é essa, presente no contexto de um espaço urbano consolidado, que deveria proteger a população e garantir relações de confiança? Para Bauman, a vulnerabilidade é, provavelmente, incurável para um tipo de sociedade em que a relativa igualdade de direitos políticos e a igualdade social formalmente reconhecida caminham de par com uma enorme diferenciação em termos genuínos de poder, posses e educação; uma sociedade em que todos "têm direitos de se considerarem iguais a todos os outros, embora sendo, de fato, incapazes de se igualar a eles" (BAUMAN, 2009, p. 38).

$\mathrm{Na}$ compreensão da condição ambiental da cidade, podemos considerar um movimento constante de transformação das áreas urbanas alimentada pelas tendências da moda, que sustentam o capital simbólico ${ }^{4}$. Em contraponto a esta

\footnotetext{
${ }^{4}$ Capital simbólico, acumulado através da especulação imobiliária, responsável pelos fenômenos urbanos como a gentrificação, a produção de comunidades/identidades territoriais e na reabilitação da paisagem urbana (HARVEY, 2015).
} 
destruição e demolição, promovida pela especulação e pela obsolescência, surgem alternativas para frear a rápida mudança através da preservação dos monumentos urbanos, que se oferecem como elementos primários, pontos fixos na dinâmica urbana. Estas referências urbanas patrimoniais deveriam servir como memória de um passado para, quem sabe, permitir um posicionamento estável diante a ameaça das mudanças impostas pelo capital (HARVEY, 2008).

Tratando sobre a perda do valor artístico pela reprodutibilidade técnica efêmera, Benjamin (1987) reflete sobre o processo autônomo de repetição e transitoriedade de imagens e representações, que antes do século 19 eram consagrados como arte, ou mesmo como memória. Esta produção, que antes era individual e manual, tende a ser construída para a coletividade como incremento da técnica, "orientando a realidade em função das massas e as massas em função da realidade" (BENJAMIN, 1987, p. 170). Esta autonomia e maior alcance da reprodução técnica permitiu mais rapidez na produção de imagens e cenários urbanos, apesar da infraestrutura urbana se modificar mais lentamente que a base econômica.

Dentro do contexto do final do século 20, David Harvey (2008) aponta sua preocupação em relação ao tratamento dado à superfície da cidade. Para o autor, a ampla área de superfície funciona como meio de estampar um sistema de produção arquitetônica e urbana na criação do espaço espetacular ${ }^{5}$ (DEBORD, 2003). Como se houvesse uma relação do espaço cotidiano com o efeito de teatralidade concebida entre tantas possibilidades de composição, abertas pelo ecletismo de estilos, que consagra uma cidade pós-moderna como simulacro esquizofrênico.

De um ponto de vista especifico, Michel Serres (2011) considera a apropriação do espaço por meio da poluição, seja através de dejetos de esgoto e de indústrias, ou pela própria poluição das cidades através das imagens publicitárias, de ruídos e odores propagados constantemente. Ainda, para o autor, a depredação

\footnotetext{
5 Para Guy Debord (2003), em "A Sociedade do Espetáculo", publicada originalmente na década de 1960, o espetáculo não é apenas as imagens, mas a relação social entre as pessoas mediada por imagens, tornando o espetáculo parte da sociedade e instrumento de unificação. "O conceito de espetáculo unifica e explica uma grande diversidade de fenômenos aparentes. As suas diversidades e contrastes são as aparências organizadas socialmente, que devem, elas próprias, serem reconhecidas na sua verdade geral. Considerado segundo os seus próprios termos, o espetáculo é a afirmação da aparência e a afirmação de toda a vida humana, socialmente falando, como simples aparência. Mas a crítica que atinge a verdade do espetáculo descobre-o como a negação visível da vida; uma negação da vida que se tornou visível" (DEBORD, 2003, p. 16).
} 
do ambiente natural é, portanto, uma maneira de estabelecer-se como proprietário, definindo fronteiras e excluindo os concorrentes.

Com o propósito de reduzir esta percepção sobre a cidade, atualmente, surgem concepções relativas ao planejamento urbano, que discutem a reconciliação dos meios de edificação com a natureza, quando procuram atender aos objetivos de uma cidade socialmente justa e ambientalmente sustentável (REIS, 2011). Esta busca que motiva parte da sociedade pela reconciliação com a natureza é algo recente, advinda do final do século 20 e início do século 21. Por isso, pela diferença entre causas e efeitos seria mais adequado afirmar que "hoje em dia, a pesquisa urbana é orientada, principalmente, pelas prioridades dos gestores do Estado e pelas preocupações da mídia dominante" (WACQUANT, 2010, p. 54).

Portanto, talvez os conceitos de sustentabilidade sejam apenas um meio encontrado pelo sistema produtivo de dizer que a apropriação do espaço ainda não urbanizado é algo inevitável. Principalmente, no uso de técnicas menos agressivas de apropriação e "poluição suave" (SERRES, 2011, p. 59).

É importante observar que a marcação do território para estabelecer uma propriedade constitui os fundamentos da civilização moderna. A formação da perspectiva de organização da sociedade moderna não admite nem mesmo a existência de uma natureza humana. Homens e mulheres deveriam se limitar como seres racionais, enquanto suas leis não deveriam ser medidas pela subjetividade. Nesta direção, a constituição da cosmovisão moderna, que antecede a maneira de ser e estar na contemporaneidade, predispõe a permanente separação entre o ser humano e a natureza, por considerar que a natureza é um atributo de maldade, fraqueza e está envolvida com o pecado.

Observamos esta condição do pensamento na raiz da ciência moderna, apresentada por Francis Bacon [1561-1626] e René Descartes [1596-1650], onde nasce, objetivamente, a lógica de domínio sobre a natureza. Por isso, na concepção destes pensadores-cientistas, o ser humano torna-se melhor à medida que se afasta da natureza. A política também se torna um rompimento com o estado de natureza humana. E a partir da razão busca-se o afastamento do orgânico, abdicando do corpo e das emoções, na busca da verdade e da evolução da existência humana. Uma verdade que estabelece seu princípio fundamentado ao artificial, ou seja, ao não humano. Por isso, é possível interpretar que o modelo global de racionalidade 
torna-se um caminho de restrições totalitárias para a sociedade alcançar a verdade e o bem comum (SANTOS, 1997). No contexto de apropriação territorial, Ana Claudia Cardoso (2011) em seu artigo sobre o desafio urbano na Amazônia, demonstra o quanto a economia local desta região é subdesenvolvida economicamente (na comercialização da produção rural ou extrativista) devido ao controle territorial de base burocrática, que dita como prioridade o abastecimento das demandas globais onde se concentra o poder soberano.

Para Boaventura de Sousa Santos (1997), o pensamento científico, baseado na racionalidade e na busca da verdade absoluta, define um totalitarismo na maneira de interpretar a realidade, que não poderia estar restrita em classificações sistemáticas. A ciência baseada na formulação de leis tem como pressupostos o ideal de ordem, estabilidade e a ideia de que o passado se repete no futuro, projetando sua sombra sobre o presente. Entretanto, este paradigma científico e racional vem sendo questionado pelo seu rigor, que desconsidera dimensões qualitativas na observação dos fenômenos e na problematização do juízo de valor humano diante dos limites do conhecimento. Ou seja, apesar da suposta liberdade individual conquistada pela modernidade, esta sensação de livre movimento e pensamento precisa estar amparada pelo sentimento de acolhimento e solidariedade, que nos torna comuns (AGAMBEN, 2013). Em situações de conflitos e disputas por territórios e representações urbanas, por exemplo, a empatia e a capacidade de reconhecimento da diversidade surgem como efeitos psicológicos importantes, possibilitando ações de solidariedade e convivência mais hospitaleira. A busca do equilíbrio entre a gentileza e a hostilidade, neste sentido, revelam diferentes faces da humanidade. Na ausência desta harmonia surge a crise do modelo de racionalidade, diante de problemas sociais para os quais não se encontram respostas compatíveis com as demandas advindas da complexidade da vida global, vinculando diferentes culturas, geografias, biodiversidade e questionamento ontológico (SANTOS, 1997).

Problemas ambientais e conflitos de ordem espacial e territorial costumam ser visibilizados quando surgem "soluções sustentáveis", que transformam o problema em oportunidade de negócio. Neste caso, o conceito de sustentabilidade ambiental também pode ser analisado como semântica aberta e indeterminada, que permite uma interpretação polissêmica nas formulações acadêmicas e nas decisões sobre o 
planejamento da cidade (BRITO, 2008). Esta concepção teleológica constitui a possibilidade de ampliar as mesmas atuações do desenvolvimento capitalista sob um novo rótulo, ou seja, mudando a embalagem para preserva a mesma estrutura de controle sobre o planejamento urbano e de regulamentação da sociedade.

Nas áreas urbanas, o racionalismo instrumental formula respostas à degradação ambiental através de ações amparadas pelos conceitos indeterminados de sustentabilidade e de sociedade de risco. Todos estes instrumentos racionais, reelaborados a partir dos pressupostos modernistas, não são diferentes das prerrogativas científicas de Bacon e Descartes, quando justificaram soluções e transformações para implantar a sociedade moderna, que se formava com o Renascimento, substituindo a cidade medieval, de base comercial, artesanal e bancária (ASSMANN; VERNAL, 2015; LEFEBVRE, 2001; SANTOS, 1997).

Consideramos que a comunicação e a segurança, encontradas no âmbito coletivo, são fundamentais para os interesses da vida comunitária. Favorecer a boa convivência urbana e o reconhecimento dos diferentes interesses, que formam a melhor perspectiva social, pode ser um dos caminhos para a primazia do planejamento urbano, não reduzido apenas na espacialização da eficiência produtiva. O direito à cidade, portanto, não está na primazia das relações econômicas herdadas da modernidade, mas em melhorar as relações humanas por uma lógica de produção espacial subordinada mais ao valor de uso e menos ao valor de troca (TRINDADE, 2012; LEFEBVRE, 2001).

Portanto, na formação do pensamento ocidental podemos considerar que não existe uma vinculação intrínseca entre a verdade e o bem, promovidos pela razão e pelo desenvolvimento. Ou será que podemos considerar qualquer princípio científico, método sistemático e desenvolvimento tecnológico como verdades absolutas? Será que a invenção da bomba atômica e das armas químicas poderia obter outro destino além da finalidade bélica? O que garante que desenvolver tecnologias de sustentabilidade urbana reconciliará a humanidade com a natureza? 


\section{VIVER PELA TÉCNICA}

Talvez a intenção de reconciliar a natureza com a humanidade - ou ainda, pela visão sustentável, de equilibrar a intervenção da humanidade sobre a natureza seja uma falsa justificativa para nos desviar da verdade e suprimir a potência de novos modelos de vida coletiva.

Como argumentamos anteriormente, o princípio da racionalidade que leva a humanidade a desenvolver componentes tecnológicos é o mesmo que inverte a ordem da humanidade como meio para alcançar o seu fim, colocando como prioridade a constituição de produtos de bens de consumo para a apropriação ilimitada dos recursos naturais.

Estes atributos técnicos recriam cenários e alimentam a imaginação na busca de maior tempo e mais conforto para a sobrevivência dos corpos moldados para trabalhar nesta sociedade. Inclusive, este sistema de avanços técnicos são os mesmos que garantem o estado pleno de salubridade, longevidade e felicidade, de acordo com as estratégias da biopolítica. Entretanto, a técnica permanece como o sagrado da concepção da modernidade, definindo a condição do pensamento e da estrutura social e justificando os meios de produção e criação de uma realidade racional, eficiente, funcional e objetiva.

Para Alberto Cupani (2013, p. 93), a técnica "designa o controle ou a transformação da natureza pelo homem, utilizando conhecimentos pré-científicos", que acompanham o desenvolvimento da humanidade. Enquanto essência da ciência, a técnica surge como meio de manipulação e transformação do mundo. Um sentido de transformação que vai do natural para o artificial. Um meio técnico que também define o seu fim, que configura, qualifica e direciona a produção da vida. Ao mesmo tempo, uma variação qualitativa radical pelo aumento quantitativo (GALIMBERTI, 1999).

Diante deste crescimento alienante da reprodução tecnológica nos falta uma concepção ética que responda às questões relativas à inovação. Devido à ausência desta consciência reflexiva, qualquer interesse técnico torna-se viável por si só mesmo que coloque em risco a vida dos seres humanos e do próprio planeta.

A escolha da racionalidade, que interpreta a realidade e estrutura sua compreensão, também define o perfil científico e tecnológico, amparando a 
constituição de um corpo orgânico multifacetado e intersubjetivo. Esta racionalidade estabelece contrastes marcantes, que impedem interpretações relativas, interdisciplinares e transitórias. São abordagens racionais desvinculadas do suporte emocional e humano, na mediação dos diferentes meios de percepção. O que reflete um contingente de seres humanos míopes, que apenas destacam conveniências na leitura da complexidade (FOUCAULT, 2006; DUFOUR, 2001).

Neste sentido, a técnica surge, não apenas, como medida de sobrevivência, mas como medida de sucesso. Como se a humanidade estivesse, cada vez mais, se especializando no desenvolvimento técnico para alcançar o topo de uma hierarquia idealizada de ordem social. Neste caso, assumindo os mecanismos técnicos (ou tecnológicos) como extensões do corpo orgânico e transformando-se em instrumento artificial e sagrado na superação de sua natureza biológica, na medida em que esta condição possa ser negada ou esquecida (AGAMBEN, 2007).

A subjetivação da técnica, neste sentido, pode ser representada pela criação da imagem do super-herói e do seu poder sagrado vinculado ao corpo. Poderes diluídos em mecanismos técnicos que facilitam a execução do trabalho e do desempenho físico, assim como, o alicate, a prótese, as armas de fogo, o arco e a flecha, os aparelhos dentários, o óculos, o implante de silicone, o smartphone, o automóvel e a arquitetura. Vários instrumentos criados como extensão do corpo para promover maior desempenho funcional e estético. Mesmo que esta potência instrumental esteja desvinculada do corpo.

Em uma proporção não tangível para a escala do corpo, o maior elemento desta articulação tecnológica é a infraestrutura urbana - enquanto complexo mecanismo de interações coletivas, que permite ampliar os limites de intervenção sobre os recursos materiais. Inclusive, na maneira como são definidos os territórios de atuação, as zonas de controle e mantendo distância (física e simbólica) com a concepção de uma natureza ameaçadora.

Diante deste panorama, as gerações que nascem no espaço urbano da atualidade estão envolvidas em um estado de adaptação permanente, onde as melhores condições de sobrevivência são diretamente proporcionais à alienação da condição de vida estabelecida advindas da modernidade. A eliminação dos contrastes sociais, do dissenso político e a pasteurização estética repercute nos valores sociais do cotidiano, principalmente, na maneira como a sociedade se 
estratifica por hierarquias de classe, de gênero e da própria condição do corpo, segmentando a vivência de identidades de grupo para justificar a necessidade de segurança e conforto - mantido por um ciclo endógeno.

A percepção destas transformações no cotidiano contemporâneo já não causa mais estranhamento. Enquanto no início do século 20, o sociólogo alemão Georg Simmel (1979) questionou como a personalidade individual se adequava ao ajustamento das forças externas presentes na metrópole moderna, hoje é possível considerar que ultrapassamos esta condição de choque pela experiência corporal e psicológica diante da modernidade e do desenvolvimento técnico, e entramos no atual estado de anestesiamento proporcionado pela experiência do ambiente artificial ininterrupto (JACQUES, 2012).

Em seu texto sobre "identidade sem pessoa", Agamben (2009) argumenta sobre a perda desta noção de particularidade e do não reconhecimento da vida como valor fundamental. Para isso, o autor cita o caso extremo dos prisioneiros de Auschwitz, que após certo período permanecendo sob tortura e violência nos campos de concentração, já não possuíam nome e nem nacionalidade. Seus corpos eram identificados através de números tatuados nos braços. Processo de desumanização não muito diferente de cidadãos contemporâneos, vítimas dos recorrentes acidentes de trânsito nas cidades, a serem identificados como dados estatísticos pelos noticiários e como dados biométricos de um sistema de controle social. Situações de banalização da vida (e da morte) de seres humanos e não humanos, que relativizam os valores morais, diante da dificuldade em demonstrar simpatia ou mesmo de entender a perspectiva do sofrimento dos outros.

É neste sentido que, através do tempo dedicado para a comunicação pelas mídias digitais, constata-se que o ser humano vive limitado em sua percepção sobre a vida, envolvido nas circunstâncias cotidianas de uma sociedade tecnocrática, voltada para artifícios de uma vida sem aura (BENJAMIN, 1987). Para que isso se mantenha, existe uma condição de alienação consentida na maneira como as pessoas estão acostumadas a perceber as relações entre o tempo e o espaço, que torna qualquer percepção humana limitada para a compreensão dos ritmos da 
natureza ${ }^{6}$ e de uma concepção ética voltada para a noção de que vivemos num só mundo (SINGER, 2004b).

\section{REFLEXÕES FINAIS}

Para refrear a influência massiva da racionalidade em nossa sociedade ocidental, a arte surge como meio de resgatar uma subjetividade perdida e para a transformação de um corpo representativo em constituir uma identidade entre o comum e o próprio (AGAMBEN, 2013). Esta resolução do indivíduo, enquanto processo de se descobrir como obra de arte, também diz respeito ao reconhecimento do outro, entre condutas sociais de tolerância e respeito, dependendo do grau de proximidade e dependência social. O que define possibilidades para a formação do senso ético por convicção, na conduta aleatória entre grupos sociais.

Complementar a esta perspectiva, Martin Heidegger (1997) considera que a essência da humanidade pelo viés do desenvolvimento da técnica repousa em sua armação, que na atualidade se encontra vinculada as redes sociais. Por isso, com toda a sua estrutura de viabilidade (econômica, política, cultural e material) esta mesma armação impede o aparecer da verdade sobre a técnica. Na medida em que a armação é um modo destinado a desabrigar o que desafia, podemos entender que o desafiar não é um consentir. Neste caso, o consentir seria a possibilidade intrínseca de emergir a salvação, seja para elevar a dignidade da essência humana, atrelada com a essência da técnica; ou para estabelecer uma nova confiança e olhar, sob a responsabilidade da poesia e da essência artística. Nesta perspectiva, a obra de arte surge como contraponto ao pensamento científico, resgatando o pensar significativo e a aura da figura singular, servindo ainda como apoio para fugir da armação técnica, que nos encaminha para um destino comum: o encarceramento do corpo pelo artifício da cidade.

\footnotetext{
${ }^{6}$ Ritmos de crescimento e de mutação, movimento aleatório e orgânico da natureza, que não corresponde à concepção dos animais como seres máquinas e autômatos, apresentado por René Descartes na primeira metade do século XVII (SINGER, 2004a).
} 


\section{REFERÊNCIAS}

AGAMBEN, Giorgio. A Comunidade que Vem. Tradução de Cláudio Oliveira. Belo Horizonte: Autêntica, 2013.

Nudità. Tradução de Selvino Assmann. Nottetempo, 2009.

Profanações. São Paulo: Boitempo, 2007, p. 65-79.

ARENDT, Hannah. O que é Liberdade? In: Entre o Passado e o Futuro. São Paulo, 2000.

ASSMANN, Selvino J. VERNAL, Javier I. (Universidade Federal de Santa Catarina, Departamento de Pós-graduação em Filosofia e Doutorado Interdisciplinar em Ciências Humanas. Florianópolis/SC/BR). Revisitando Natureza Humana versus Condição Humana. Aula proferida na disciplina Teoria da Sociedade, da Política e da Natureza. Programa Interdisciplinar em Ciências Humanas da Universidade Federal de Santa Catarina. Florianópolis: UFSC, jun. 2015.

BAUMAN, Zygmunt. A Arte da Vida. Tradução de Carlos Alberto Medeiros. Rio de Janeiro: Zahar, 2009.

BAZZANELLA, Sandro Luiz. ASSMANN, Selvino José. A vida como ponto de inflexão entre o pensamento de Nietzsche e Agamben. In: A vida como potência a partir de Nietzsche e Agamben. São Paulo: Editora LiberArs, 2013, p. 35-99.

BENJAMIN, Walter. Passagens. Tradução de Irene Aron. Belo Horizonte: Editora UFMG; São Paulo: Imprensa Oficial do Estado de São Paulo, 2009.

. A obra de arte na era de sua reprodutibilidade técnica [primeira versão]. In: Magia e técnica, arte e política: ensaios sobre literatura e história da cultura. Obras escolhidas, vol. 1. Tradução de Sergio Paulo Rouanet. 3.ed. São Paulo: Editora Brasiliense, 1987, pp. 165-196.

BERLIN, Isaiah. Quatro Ensaios Sobre a Liberdade. Brasília: Editora da Universidade de Brasília, 1969, p. 133-175.

BRANDÃO, Ludmila. Da cidade moderna às contemporâneas: notas para uma crítica do urbanismo modernista. In: Revista Territórios \& Fronteiras. Cuiabá, v. 7, n. 1, p. 247-271, 2014.

BRITO, Jadir. Conflitos Socioambientais Urbanos e o Enfrentamento Socialista aos Modelos Neoliberais de Ecoeficiência na Luta pela Moradia Digna. In:

Suplemento Eletrônico: Socialismo, Liberdade e Poder Local [internet]. Fundação Lauro Campos, Rio de Janeiro, 2008 [citado em 2008 Mar 26]. Disponível em $<$ http://laurocampos.org.br/2008/03/conflitos-socioambientais-urbanos-e-oenfretamento-socialista-aos-modelos-neoliberais-de-ecoeficiencia-na-luta-pelamoradia-digna/> Acesso em: set. 2017. 
BUTLER, Judith. Quadros de Guerra: quando a vida é passível de luto? Tradução de Sérgio Tadeu de Niemeyer Lamarão e Arnaldo Marques da Cunha. 1.ed. Rio de Janeiro: Civilização Brasileira, 2015.

CARDOSO, Ana Cláudia. O Problema das Escalas e o Desafio do Urbano na Amazônia Oriental. In: REIS, Almir Francisco (Org.). Arquitetura, Urbanidade e Meio Ambiente. Florianópolis: Editora da UFSC, 2011, pp. 67-87.

CUPANI, Alberto. Filosofia da Tecnologia: um convite. 2.ed. Florianópolis: Editora da UFSC, 2013.

DEBORD, Guy. A Sociedade do Espetáculo. Tradução de Estela dos Santos Abreu. Rio de Janeiro: Editora Contraponto, 1997.

DUFOUR, Dany-Robert. Os Extravios do Indivíduo-sujeito. Tradução de Selvino Assmann. In: Le Monde Diplomatique. Paris, fev. 2001.

FOUCAULT, M. Omnes et Singulatim. Para uma crítica da razão política. Tradução de Selvino Assmann. Florianópolis: Nephelibata, 2006.

GALIMBERTI, Umberto. A Emergência Tecnológica e a Passagem da Cosmo-polis para a Tecno-polis. Tradução de Selvino Assmann (Revista Interthesis). In: Psiche e Techne. L'uomo nell'età dela tecnica. Roma: Feltrinelli, 1999.

HARVEY, David. Paris: capital da modernidade. 1.ed. São Paulo: Boitempo, 2015, p. 281-299.

Condição Pós-moderna: uma pesquisa sobre as origens da mudança cultural. Tradução de Adail Ubirajara Sobral e Maria Stela Gonçalves. 17.ed. São Paulo: Edições Loyola, 2008.

HEIDEGGER, Martin. A Questão da Técnica. São Paulo: USP, 1997, p. 40-93.

JACOBS, Jane. Morte e Vida nas Grandes Cidades. Tradução de Carlos S. Mendes Rosa. $3^{\mathrm{a}}$ ed. São Paulo: Editora WMF Martins Fontes, 2011.

JACQUES, Paola Berenstein. Elogio aos Errantes. Salvador: EDUFBA, 2012.

JAMESON, Fredric. A Cultura do Dinheiro: ensaios sobre a globalização. Tradução de Maria Elisa Cevasco e Marcos César de Paula Soares. Petrópoles, RJ: Vozes, 2001.

LEFEBVRE, Henri. O Direito à Cidade. Tradução de Rubens Eduardo Frias. São Paulo: Centauro, 2001.

REIS, Almir Francisco (Org.). Arquitetura, Urbanidade e Meio Ambiente. Florianópolis: Editora da UFSC, 2011. 
SANTOS, Boaventura de Sousa. Um Discurso Sobre as Ciências. 9.ed. Lisboa: Afrontamento, 1997.

SÊGA, Rafael Augustus. Os Melhoramentos Urbanos como Estratégias de Dominação Social. In: Anos 90. Porto Alegre, n. 14, p. 218-230, dez. 2000

SERRES, Michel. O mal limpo: poluir para se apropriar? Tradução de Jorge Bastos. Rio de Janeiro: Bertrand Brasil, 2011.

SIMMEL, Georg. A Metrópole e a Vida Mental. In: VELHO, Otávio Guilherme (Org.). O Fenômeno Urbano. 4.ed. Rio de Janeiro: Zahar, 1979, p. 11-25.

SINGER, Peter. Libertação Animal. Tradução de Marly Winckler. Porto Alegre: Lugano Editora, 2004a.

. Um Só Mundo: a ética da globalização. Tradução de Adail Ubirajara Sobral. São Paulo: Martins Fontes, 2004b.

TRINDADE, Thiago Aparecido. Direitos e Cidadania: reflexões sobre o direito à cidade. In: Lua Nova. São Paulo, n. 87, p. 139-165.2012,

WACQUANT, Loïc. Ressituando a Gentrificação: a classe popular, a ciência e o Estado na pesquisa urbana recente. In: Caderno CRH, v. 23, n. 58. Salvador, jan/abr. 2010, pp. 51-58.

Artigo recebido em: 10/09/2017

Artigo aprovado em: 30/11/2017

Artigo publicado em: 18/12/2017 